\title{
Effect of Family Structure on Life Satisfaction: Australian Evidence*
}

\author{
M. D. R. Evans and Jonathan Kelley \\ Melbourne Institute of Applied Economic and Social Research \\ The University of Melbourne
}

Melbourne Institute Working Paper No. 24/04

ISSN 1328-4991 (Print)

ISSN 1447-5863 (Online)

ISBN 0734031661

September 2004

*We would like to thank the Department of Family and Community Services for funding this research. The views expressed in this paper are those of the authors and do not represent the views of the Minister for Family and Community Services, the Department of Family and Community Services or the Commonwealth Government.

Melbourne Institute of Applied Economic and Social Research

The University of Melbourne

Victoria 3010 Australia

Telephone (03) 83442100

Fax (03) 83442111

Email melb-inst@unimelb.edu.au

WWW Address http://www.melbourneinstitute.com 


\begin{abstract}
How do family arrangements affect subjective wellbeing? We investigate this issue using data from a representative national sample of Australia $(\mathrm{N}=26,009)$. Our results suggest that commitment is the key: the security and legal recognition of a formal marriage makes both women and men happier. Thus the traditional pattern of life-long marriage increases the sum of human happiness. A less traditional pattern of early divorce followed by an enduring second marriage is little worse. But the increasingly common modern patterns of divorce without remarriage, or long lasting co-habitation without formal marriage, reduce the sum of human happiness by $5 \%$ to $10 \%$ for both women and men.
\end{abstract}




\section{Effect of Family Structure on Life Satisfaction: Australian Evidence}

How do family arrangements affect subjective well being? Most people are happy all around the world (Cummins 1998; Wearing and Headey 1998), but a variety of hypothesis from a variety of social science disciplines suggest that family structure is one of the most important determinants of life satisfaction. This is increasingly important in recent decades as, throughout most of the developed world, the traditional family has declined and family arrangements become more diverse: more people delay marriage or eschew it altogether and live as couples without marrying; people have fewer children; divorce is increasingly common; and after divorce many spend lengthy periods living alone or as unmarried couples before remarrying (Australian Bureau of Statistics 2000; Castles 1998: 264-299). This paper investigates the impact of these diverse family structures on well being, including the possibility that family structure affects men and women differently, using data from a series of large, representative national samples of Australia $(\mathrm{N}=26,009)$.

Plan of the paper. The first section briefly reviews the main theories linking family structure and well-being and sets out their (conflicting) predictions. The second describes the data. The third describes our measure of well-being and assesses whether conventional equal-interval scoring is appropriate. The fourth section gives our main results, which are best explained by commitment theory. The fifth section looks briefly at the quality of marriage. The final section discusses the implications.

\section{Theories}

One traditional institutionalist perspective sees commitment as the central feature of marriage: it is the public commitment, social and legal reinforcement of that commitment, and consequent expectation of long term stability that makes formal marriage distinctively rewarding (e.g. Diener et al 2002; Mastekaase 1993; Waite and Gallagher 2000). ${ }^{1}$ Table 1 sets out the implications. Specifically:

H1. Commitment: Marriage makes people happier, because the security and legal recognition of a formal marriage makes for

\footnotetext{
${ }^{1}$ An analogous argument holds that job security has a major impact on subjective quality of employment and perhaps more surprisingly - on subjective satisfaction with income and standard of living. There is strong empirical evidence in support of this hypothesis (e.g. Kelley, Evans, and Dawkins 1998).
} 
committed, loving personal relationships. Thus married people are happier than single people; unwed couples (those living together without being married) are not as happy as married couples, because commitment is problematic; divorced people will be less satisfied than those in any other situation, since broken commitments are highly distressing; widows will be similar to single people, since widowhood involves no broken commitment; and second marriages will be just as happy as first marriages since, since they are as stable and legally recognized as first marriages.

This is our preferred hypothesis because abundant prior research supports most of its predictions. Prior research tends to show that married people are happier than others in the United States (Andrews and Withey 1976; Davis 1984; Haring-Hidore, Stock, Okun and Witter 1985; Waite and Gallagher 2000 p. 67) and elsewhere (Diener et al 2000; Veenhoven 1984). This finding derives additional strength from longitudinal studies controlling for prior subjective well-being (Marks and Lambert 1998). Moreover, prior research suggests that the divorced are worse off than singles, and much worse off than married people (Maastekaasa 1994; Waite and Gallagher 2000 p. 67), results bolstered by longitudinal studies controlling for prior subjective well-being (Marks and Lambert 1998; Mastekaasa 1995).

Another school of thought discounts institutional commitments, suggesting instead that pair bonding is the essential aspect of marriage: companionship, sex, and the economies of scale provide the key benefits, which couples can enjoy whether or not they are legally married (e.g. Headey 1993; Macklin 1978; Marks and Fleming 1999; see Table 1, Row 2).

H2. Pair bonding: People derive subjective well-being from pair bonding, while the security and legal recognition of formal marriage is irrelevant to quality of life. Thus married people and unwed couples will be equally satisfied with their lives, and, moreover, happier than the single, the divorced, or the widowed. Second marriages will be just as happy as first marriages. There will be no significant differences in subjective well-being between the single, the divorced, and the widowed since all lack pair bonds. 
Table 1. Theory. Predictions about whether each group is better off (++), the same (0), or worse off (--) than single people, other things being equal (first panel). Correct predictions highlighted. Summary of findings from previous research and from our analyses (last two panels)

\begin{tabular}{|c|c|c|c|c|c|c|c|}
\hline & \multicolumn{6}{|c|}{ Predictions } & \multirow[b]{2}{*}{$\begin{array}{r}\% \text { correct } \\
\text { predictions }\end{array}$} \\
\hline & $\begin{array}{c}\text { First } \\
\text { marriage }\end{array}$ & $\begin{array}{l}\text { Unwed } \\
\text { couple }\end{array}$ & Divorced & Widowed & $\begin{array}{l}\text { Second } \\
\text { marriage }\end{array}$ & Children & \\
\hline \multicolumn{8}{|l|}{ Hypotheses } \\
\hline H1. Commitment & ++ & 0 & -- & 0 & ++ & ?? & $100 \%$ \\
\hline H2. Pair bonding & ++ & ++ & 0 & 0 & ++ & ?? & $60 \%$ \\
\hline H3. Selectivity & + & + & -- & 0 & -- & $? ?$ & $60 \%$ \\
\hline H4. Reproductive fitness & ++ & 0 & 0 & 0 & + & +++ & $67 \%$ \\
\hline H5. Postmaterialism & -- & ++ & 0 & 0 & -- & -- & $17 \%$ \\
\hline $\begin{array}{l}\text { H6. Divergent preferences } \\
\text { with gender equality }\end{array}$ & 0 & 0 & - & -- & 0 & 0 & $50 \%$ \\
\hline \multicolumn{8}{|l|}{$\begin{array}{l}\text { H7. Divergent preferences \& } \\
\text { male domiance }\end{array}$} \\
\hline Women & -- & - & 0 & 0 & -- & ?? & $40 \%$ \\
\hline Men & ++ & + & 0 & 0 & ++ & $? ?$ & $60 \%$ \\
\hline \multicolumn{8}{|l|}{$\begin{array}{l}\text { H8. Divergent preferences \& } \\
\text { female domiance }\end{array}$} \\
\hline Women & ++ & 0 & 0 & 0 & ++ & ?? & $80 \%$ \\
\hline Men & -- & - & 0 & 0 & -- & $? ?$ & $20 \%$ \\
\hline Prior research & $++[\mathrm{a}]$ & $0[b]$ & $--[c]$ & ??[d] & $+?[\mathrm{e}]$ & $0 ?[\mathrm{f}]$ & \\
\hline \multicolumn{8}{|l|}{ Results for Australia[f] } \\
\hline All $(N=26,009)$ & +4.4 & n.s. & -4.5 & n.s. & +4.0 & n.s. & \\
\hline & $t=10.58$ & $t=-1.22$ & $t=7.16$ & $t=-0.61$ & $t=6.31$ & $t=1.90$ & \\
\hline Women $(\mathrm{N}=13,011)$ & $\begin{array}{r}+3.8 \\
t=6.09\end{array}$ & $\begin{array}{l}-2.3 \\
t=-2.71\end{array}$ & $\begin{array}{c}-6.0 \\
t=-6.81\end{array}$ & $\begin{array}{c}\text { n.s. } \\
t=-.06\end{array}$ & $\begin{array}{c}+3.5 \\
t=3.74\end{array}$ & $\begin{array}{c}\text { n.s. } \\
t=0.03\end{array}$ & \\
\hline Men $(\mathrm{N}=12,728)$ & $\begin{array}{r}+4.71 \\
t=8.21\end{array}$ & $\begin{array}{c}\text { n.s. } \\
t=0.95\end{array}$ & $\begin{array}{c}-3.0 \\
t=-3.3\end{array}$ & $\begin{array}{c}\text { n.s. } \\
t=-1.63\end{array}$ & $\begin{array}{l}+4.1 \\
t=4.69\end{array}$ & $\begin{array}{c}0.4 \\
t=2.75\end{array}$ & \\
\hline
\end{tabular}

[a] Andrews and Withey 1976; Davis 1984; Haring-Hidore, Stock, Okun and Witter 1985; Diener et al 2000; Marks and Lambert 1998; Veenhoven 1984; Waite and Gallagher 2000 p. 67.

[b] Bennett, Blanc, and Bloom 1988; Maastekaasa 1994; Marks and Fleming 1999; Rindfuss and VandenHeuvel 1990; Waite and Gallagher 2000 p. 67

[c] Maastekaasa 1994, 1995; Marks and Lambert 1998; Waite and Gallagher 2000 p. 67

[d] There is little evidence on this.

[e] Probably as happy as first marriages (Johnson and Booth 1998; Rogers 1999) or less happy (Kurdek 1990).

[f] Source: Tables 2 and 3

We tend to doubt the substitutability of marriage and cohabitation in light of prior research documenting rather strong differences between them. In particular, cohabitors are in many ways more similar to singles than to married people (Bennett, Blanc, and Bloom 1988; Marks and Fleming 1999; Maastekaasa 1994; Rindfuss and VandenHeuvel 1990; Waite and Gallagher 2000 p. 67). Moreover, prior research shows that the divorced have lower subjective well being than the single (Maastekaasa 1994; Marks and Lambert 1998; Waite and Gallagher 2000 p. 67).

Marriage raises important selectivity issues because people's skills at personal relations shape their chances of marrying, divorcing, and re-marrying (e.g. Cherlin 1992, p 29; see Table 1, Row 3): 
H3. Selectivity: People who are not very good at personal relations, and therefore slightly less happy while pair bonded, will predominate among the divorced, and hence among those in second marriages. Thus the divorced will be slightly less happy than the single; remarried people will be slightly less happy than those in first marriages; unwed couples will be similar to first marriages; but widows (because unselected on personal relations) will be no different than the single.

The prior evidence here is mixed, with some reporting second marriages to be less happy (e.g. Kurdek 1990) and other research finding second marriages just as happy as first marriages (Johnson and Booth 1998; Rogers 1999). ${ }^{2}$

Socio-biological arguments also have clear implications (e.g. Eaves 1990; Kirk et al. 2001;Vining 1986; see Table 1, Row 4):

H4. Reproductive fitness: Subjective well-being will increase greatly with the number of children. Because marriage is a step on the way to children, it should increase subjective well-being. Because unwed couples, the divorced, and widows are in low fertility arrangements, they should be similar to the single baseline. Since re-marriages have higher fertility than singles but lower than first marriages, they should be mildly positive.

Post materialist arguments also have implications for marriage (Inglehart 1997; see Table 1, Row 5):

H5. Post materialism: Unwed couples should be the happiest because they are free of the responsibilities and historical baggage of formal marriage while enjoying many of the benefits. Singles, the divorced and the widowed should come next. Married couples' subjective well-being will be reduced by their loss of freedom. Children will reduce well-being by limiting freedom.

The previous arguments have assumed that people all have similar preferences. But if, instead, people have diverse preferences, some preferring one marital status and others preferring different ones, then they should sort themselves into the arrangements best suited to their tastes (e.g. Becker 1991; Bennett, Blanc, and Bloom 1988; see Table 1, Row 6):

H6. Diverse preferences. People sort themselves into the family arrangements that suit them best, hence all marital statuses are

\footnotetext{
${ }^{2}$ Regardless of whether remarriage brings people quite back up to the level of subjective well-being of first marriages it is probably the best goal for divorced people to pursue, as active remediation is the coping strategy most likely to rebound subjective well-being after adversity (Headey and Wearing 1990).
} 
equally satisfying for those in them. Similarly, children should have no net impact on subjective well-being because people select the family size that is most satisfying for them. But since some divorces and almost all widowhoods remove people from their preferred states, they are less happy.

Doubts are cast on this hypothesis by research suggesting that the experience of different marital statuses affects how people feel (Marks and Lambert 1998). Consistent with this hypothesis is evidence that in general children have no net impact on subjective well-being (Oropesa 1995), but unwanted infertility impairs life satisfaction (Leiblum 1993). Nonetheless, some research suggests that children reduce life satisfaction (Wilkinson 1995), so the matter is not yet settled.

If preferences for marriage differ between men and women, and men have more power with which to enforce their wishes, then marriage will differentially benefit men (e.g. Bernard 1982; see Table 1, Rows 7 and 8):

H7. Diverse preferences with male dominance. Single men and women are about equally happy. Since marriage benefits men but not women, men in first marriages, in second marriages, and in unmarried couples are happier than single men. Women in these circumstances are less happy than single women and also less happy than their male partners. Divorce and widowhood return people to the level of subjective well-being characteristic of singles.

Doubts are cast on this hypothesis by prior research suggesting that the beneficial effects of marriage do not differ by gender (Diener et al 2000; Forest 1996; Mastekaasa 1993; Rogers 1999). There is evidence that single women are a little happier than single men (Marks and Fleming 1999).

Alternatively, some have argued that men and women have different preferences, with women benefiting from marriage and men loosing. Specifically (Table 1, Rows 9 and 10):

H8. Diverse preferences with female dominance: Women want the security of marriage while men prefer the freedom of non-marriage. Thus, women's subjective well-being is low when single; low while living as an unwed couple, since security is low; high when married; low when divorce or widowed; and high again when remarried. In contrast, men's well being is highest when single; falls when living as an unwed couple, since freedom is somewhat restricted; lower yet when married; rises again when divorced or widowed; and falls when remarried. 
Doubts are cast on this hypothesis by prior research suggesting that the beneficial effects of marriage do not differ by gender (Diener et al 2000; Forest 1996; Mastekaasa 1993; Rogers 1999; Williams 2001).

\section{Data}

Data are from the pooled International Social Science Surveys/Australia, 1984-2001, Australia's leading academic survey. The IsssA surveys, conducted annually except for a few years, are from simple random samples of Australian citizens drawn by the Electoral Commission from the compulsory electoral roll. They are conducted by mail using a modification of Dillman's (1993) Total Response Method. First, a personally addressed preliminary letter announces the survey, then the survey itself arrives in the post some weeks later. For non-respondents, this is typically followed by four follow-up mailings, two with fresh copies of the questionnaire, over a six to 12 month period. Completion rates (defined as completions as a percentage of the sum of completions and refusals) run around 60 to 65 per cent, which compares favourably with recent experience in Australia, the USA, and many other industrial nations -- for example, the well-regarded International Crime Victim Survey averaged 41 per cent in 14 nations (van Dijk, Mayhew and Killias,1990).

Benchmarking information comparing the IsssA surveys to the Census (on the limited range of variables available in the Census) shows that the survey closely resembles the population as a whole but with under representations of very young adults whose frequent movements elude the electoral rolls and of the very old, some of whom are troubled by dementia and other conditions that make survey completion difficult (Bean 1991; Sikora 1997; Evans and Kelley, 2002: Ch. 28). Further details are in Kelley and Evans (1999).

Well-being measures were included in all IsssA surveys but one which gives, after losing a few further cases to item non-response, 26,009 cases for the present analysis. Some analyses include geographical data which is available only for recent surveys, leaving 8,616 cases.

\section{Measurement}

We used the standard measure of subjective well-being. The core measure is Andrews and Withey’s life-as-a-whole index (Andrews and Withey 1976; Cantril 1965; for Australia see Headey 1988 and Headey and Wearing 1992). For similar developments in economics see Kahneman, Diener and Schwarz (1998) and the authors of the "Leyden School” (Van Praag 1971; Frijters 1999 and the references given there). A standard form of the life-as-a-whole 
index, and the one we use, combines answers to essentially the same question asked twice, with other questions about particular domain satisfactions ("standard of living", "sense of purpose and meaning in life”, “hobbies”, “neighbourhood”, etc.) asked in between:

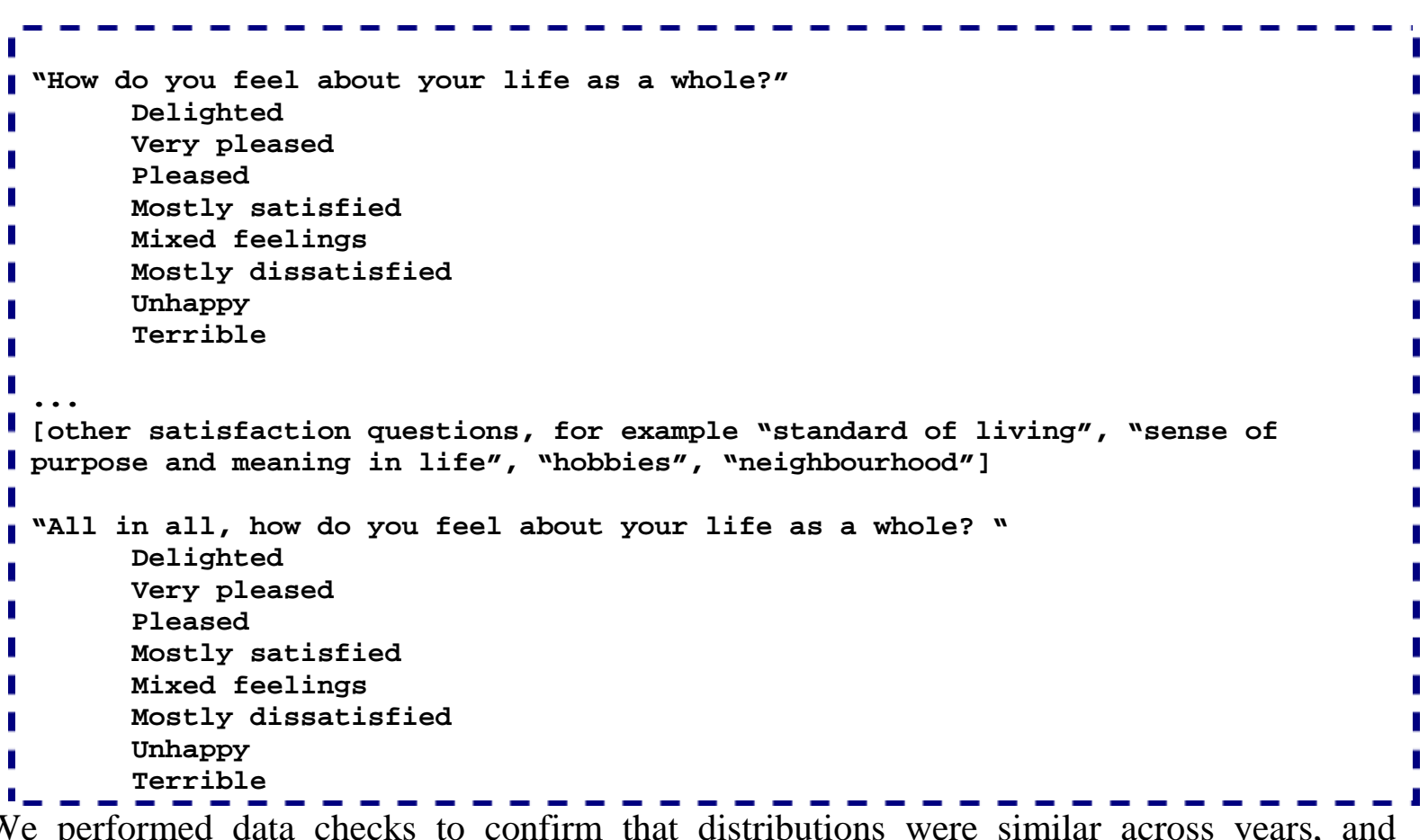
assessed the correlations among items and with criterion variables.

\subsection{Scoring the questions: Multinomial ordinal probit estimates}

Prior research in this area mostly treats the answers to subjective well-being questions as though the answer categories (“delighted”, “very pleased”, etc.) were measures directly appropriate for use as equal interval (Likert) scales in multivariate analysis, although the measures are, in fact, categorical. The key question here is whether the categories approximate equal intervals or whether their psychological distances are sufficiently unequal as to warrant a different scoring.

A convenient equal interval scoring would give "delighted" at the top a score of 100, "terrible" at the bottom a score of zero, and other categories scores at equal intervals in between:

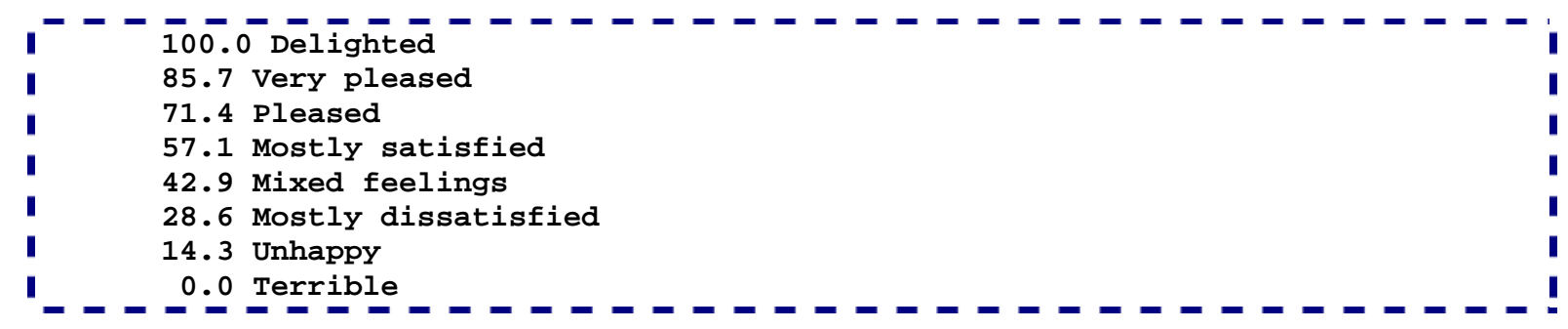


Other equal interval scores would be, for example, 1, 2, 3, 4, 5, 6, 7, 8 ("Likert”) or the reverse $8,7,6,5,4,3,2,1$, or zero to one $(0, .143, .286, \ldots, 1.000)$. All equal interval scoring schemes lead to essentially the same results: the units change in the obvious way, but can easily be converted from one to the other with no loss of information (just like the price of a computer could be expressed in cents, Australian dollars, euros, or yen without making any real difference).

What does matter is the gap between answers: the equal interval scoring assumes that the gap between (for example) "delighted" and "very pleased" is the same magnitude as the gap between (say) “unhappy” and “terrible”. In our preferred equal interval scoring shown above, that gap is 100/7 (since the 8 answer categories produce 7 gaps); in Likert scoring the gap is 1.

But is that true? It could be, for example, that people make a very large distinction between “delighted" and "very pleased" but only a small one between "unhappy" and "terrible”. It might, for example, take a $\$ 100,000$ windfall to shift some who is "very pleased” with his life to being "delighted" but only $\$ 25,000$ to shift him out of misery from "terrible" to "unhappy”. Or it could be the exact opposite, taking a lot to shift him out of misery but only a little to tip him from "very pleased” to “delighted”.

To discover how large these gaps are, we turn to an ordered probit analysis, predicting life satisfaction from some key variables. In this section we work with just one of our two global measures of life satisfaction, because we need to score them before we can combine them into a multiple-item index.

The ordinal multinomial probit regression model posits an underlying continuous linear variable, $\mathrm{y}^{*}$, that reflects respondents' unobserved true scores plus an error term:

$y^{*}=a+b_{j} X_{j}+e$

where the $X_{j}$ are $j$ observed independent variables, the $b_{j}$ are weights for them, the individual subscripts are suppressed for simplicity, and e is a normally distributed random error term. Respondents are assumed to answer the survey question by choosing the answer category closest to their underlying position, $\mathrm{y}^{*}$ :

Probability (Outcome $=i)=\operatorname{Pr}\left(\right.$ Cut $(i-1)<y^{*} £$ Cuti $)$

where i subscripts the response categories labelled by their endpoints ("cutting points"). The coefficients $b_{j}$ and the cutting points $C t_{i}$ are estimated simultaneously by maximum likelihood methods (Table 2). 
The cutting points imply a suitable scoring for the categories of the dependent variable, essentially an effect-proportional score using $y^{*}$ as the criterion. For our life satisfaction measure, these cutting points are shown in the bottom panel of Table 2.

Table 2: Scaling of life satisfaction categories: Ordinal multinomial probit estimates.[a]

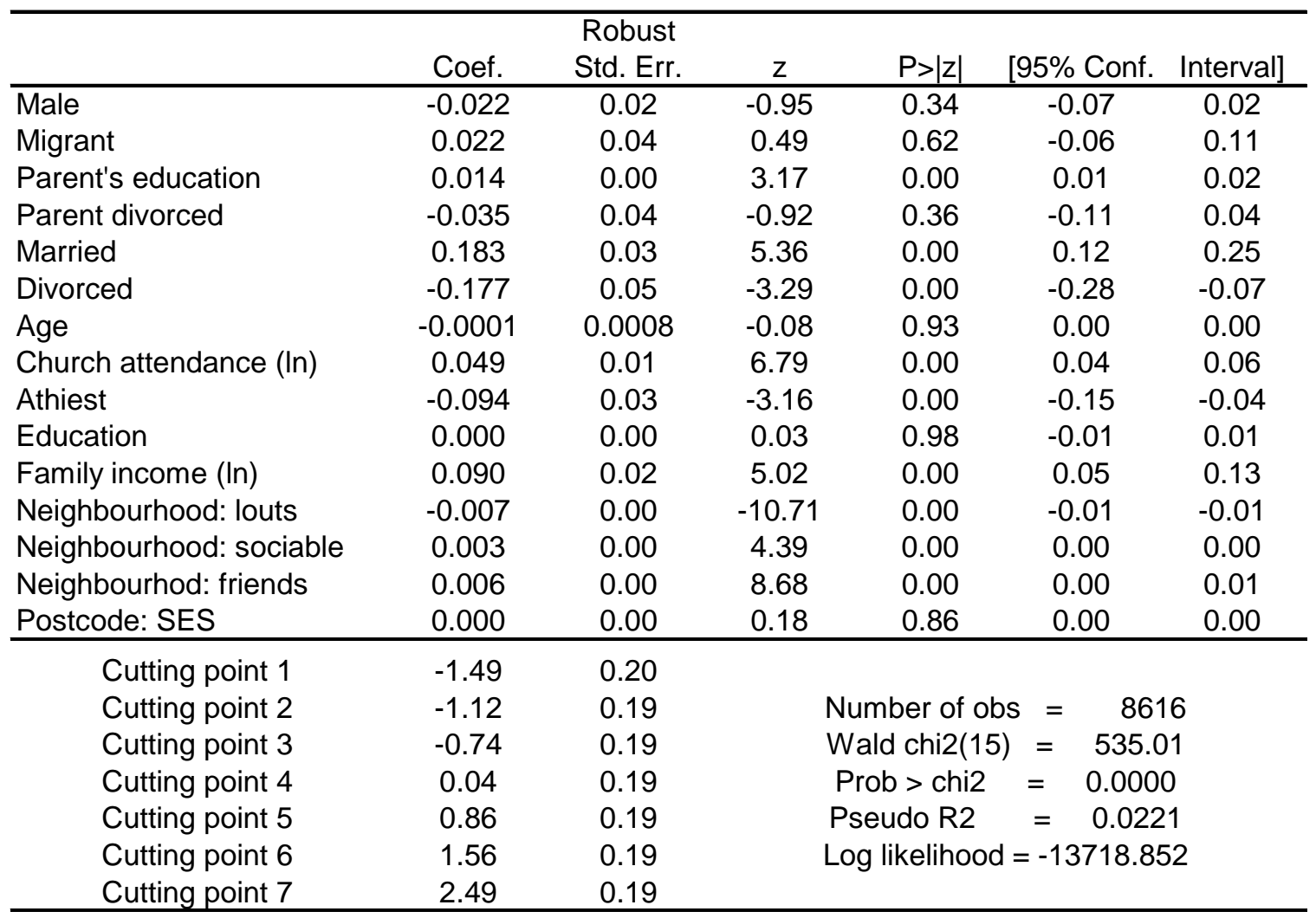

[a] $\mathrm{N}=8,616$ cases with complete information on all variables. Geographic information is available only in recent surveys.

We use this scoring, converted for clarity and without loss of generality to range from a low of zero to a high of 100, as shown in Table 3. Table 3 shows the scoring for each answer category, in a zero to 100 metric, that would come (1) from an equal interval scoring and (2) from the scoring implied by the ordinal probit analysis in Table 2.

Note first that there is a strong concentration of cases towards the top - the more satisfied answers, with $97 \%$ of the cases in the top 5 categories and only $3 \%$ scattered over the remaining three categories (column 1). This is a standard finding for life satisfaction (e.g. Headey and Wearing 1993: Ch. 4).

The second thing to notice about Table 3 is that the gap between the answer categories at the most satisfied end of the scale is smaller in the probit scoring at 4.6 points out of 100 (column 
6) than in the equal-interval scoring where the corresponding gap is 14.3 points out of 100 (column 3). Across the middle categories, the gaps implied by the probit scoring (13 to 20 points out of 100) and those from the equal interval scoring (14.3 points) are of very similar size. Towards the dissatisfied end, the gaps implied by the probit scoring are quite irregular, quite possibly because of the small case base at that end of the distribution.

Table 3: Life satisfaction: Percent distribution, equal interval scoring, and scoring implied by ordinal probit analysis.[a]

\begin{tabular}{|c|c|c|c|c|c|}
\hline \multirow[b]{2}{*}{ Percent } & \multicolumn{2}{|c|}{ Equal interval scoring } & \multicolumn{3}{|c|}{ Scoring based on ordinal probit } \\
\hline & $\begin{array}{c}\text { Equal } \\
\text { intervals }\end{array}$ & $\begin{array}{c}\text { Gap from } \\
\text { category } \\
\text { above }\end{array}$ & $\begin{array}{l}\text { Mean } \\
\text { predicted } \\
\text { value }\end{array}$ & $\begin{array}{l}\text { Implied } \\
0 \text { to } 100 \\
\text { scoring }\end{array}$ & $\begin{array}{c}\text { Gap from } \\
\text { category } \\
\text { above }\end{array}$ \\
\hline 12.8 & 100.0 & -- & 1.40 & 100 & -- \\
\hline 28.2 & 85.7 & 14.3 & 1.38 & 95 & 4.6 \\
\hline 26.1 & 71.4 & 14.3 & 1.32 & 82 & 13.3 \\
\hline 22.0 & 57.1 & 14.3 & 1.26 & 69 & 13.3 \\
\hline 8.5 & 42.9 & 14.3 & 1.17 & 49 & 19.5 \\
\hline 1.5 & 28.6 & 14.3 & 1.08 & 28 & 21.4 \\
\hline 0.6 & 14.3 & 14.3 & 1.07 & 25 & 3.0 \\
\hline 0.4 & 0.0 & 14.3 & 0.96 & 0 & 24.8 \\
\hline $100 \%$ & & & & & \\
\hline
\end{tabular}

[a] $\mathrm{N}=8,616$ cases with complete information on all variables. Geographic information is available only in recent surveys.

To assess whether the probit scoring is measurably advantageous over the equal interval scoring, we begin by comparing correlations of life satisfaction scored in these two ways with each other and with criterion variables (Table 4, columns 1 and 2).

The first important point in the comparison of the scorings is that the correlation between the two different scorings of life satisfaction is fully 0.98 . Thus the scorings implied by the two methods are very close for most of the cases.

The second important point about Table 4 is that the correlations of criterion variables with life satisfaction scored in these two different ways are very similar. For example, the correlation of with being married with probit-scored life satisfaction is .015 , and the correlation of being married with equal-interval-scored life satisfaction is 0.14 . Similarly, the correlation of church-going with life satisfaction scored both ways is identical at 0.12 . Thus, the correlations based on the two scorings with this broad array of criterion variables are so close that there is no evident advantage to the probit scoring. 
Table 4. Comparison of equal interval and probit scoring of life satisfaction. Correlations and OLS partial regression coefficients[a]

\begin{tabular}{|c|c|c|c|c|c|}
\hline \multirow[b]{2}{*}{ Variable } & \multirow[b]{2}{*}{ Units } & \multicolumn{2}{|c|}{ Correlations } & \multicolumn{2}{|c|}{ Regression } \\
\hline & & $\begin{array}{l}\text { Probit } \\
\text { scoring }\end{array}$ & $\begin{array}{c}\text { Equal } \\
\text { interval }\end{array}$ & $\begin{array}{c}\text { Probit } \\
\text { scoring }\end{array}$ & $\begin{array}{c}\text { Equal } \\
\text { interval }\end{array}$ \\
\hline \multicolumn{6}{|l|}{ Satisfaction: } \\
\hline Probit scoring & 0 to 100 & -- & -- & -- & -- \\
\hline Equal interval scoring & 0 to 100 & 0.98 & -- & -- & -- \\
\hline Male & 0 or 1 & 0.00 & -0.01 & -0.1 & -0.4 \\
\hline Migrant & 0 or 1 & -0.01 & 0.00 & 0.6 & 0.8 \\
\hline Parent's education & years & 0.03 & 0.03 & 0.24 & 0.25 \\
\hline Parent divorced & 0 to 100 & -0.05 & -0.04 & -1.5 & -1.4 \\
\hline Married & 0 or 1 & 0.15 & 0.14 & 2.8 & 2.9 \\
\hline Divorced & 0 or 1 & -0.11 & -0.10 & -3.3 & -3.1 \\
\hline Age & years & 0.04 & 0.04 & 0.014 & 0.010 \\
\hline Church attendance (In) & $\log$ & 0.12 & 0.12 & 0.81 & 0.89 \\
\hline Athiest & 0 or 1 & -0.07 & -0.08 & -1.2 & -1.3 \\
\hline Education & years & 0.04 & 0.03 & 0.1 & 0.1 \\
\hline Family income (In) & $\log$ & 0.12 & 0.11 & 1.89 & 1.85 \\
\hline Neighbourhood: louts & 0 to 100 & -0.14 & -0.14 & -0.11 & -0.11 \\
\hline Neighbourhood: sociable & 0 to 100 & 0.12 & 0.12 & 0.07 & 0.06 \\
\hline Neighbourhod: friends & 0 to 100 & 0.12 & 0.12 & 0.09 & 0.10 \\
\hline Postcode: SES & 0 to 100 & 0.03 & 0.02 & 0.01 & 0.01 \\
\hline (Constant) & & -- & -- & 51.9 & 44.3 \\
\hline
\end{tabular}

[a] $N=12,183$ cases, treating missing data by the pairwise present method but restricted to surveys with at least some geographic data available.

The regression estimates of the effects of these criterion variables on life satisfaction in the probit scoring (column 3) and in the equal-interval scoring (column 4) are also very similar. For example, divorced people are 3.3 points less satisfied with their lives than are single people in the probit scoring, and are 3.1 points less satisfied with their lives in the equalinterval scoring. Similarly, the effect of church attendance is .81 in the probit scoring and .89 in the equal-interval scoring. The discrepancies between the estimates in the two columns are small and do not systematically favour either scoring.

In sum, the comparison of the equal-interval scoring and the probit scoring of life satisfaction show that they yield very similar results and that, in particular, the probit scoring does not provide clearly stronger estimates. Following the standard scientific rule of Occam's Razor -that the simpler explanation or method is to be preferred unless a more complex alternative yields measurable advantage -- suggests that we should employ the equal interval scoring in this case. This also has the advantage of being more comparable with past research. Accordingly, we use the equal interval scoring throughout the rest of this paper. 


\section{Results}

To model the effects of family situation we take the single state - never married and not now de facto - as the reference category. The effects of the other family arrangements are then estimated relative to it.

People in intact first marriages are happier than their single peers by about 4 points out of 100 , net of other influences, a statistically significant difference (Table 5). That is not a surprising result in light of prior research, but prior research provides less guidance about subsequent marriages, in part because they have been too few to permit good estimates in smaller surveys. We find that people in second marriages are also about 4 points happier than single people. In fact, the estimates of the amounts of happiness conferred by first and second marriages are not significantly different. This is an important result, because it suggests (1) that there are no residual scars from divorce that a second marriage does not cure, at least in terms of overall life satisfaction, but that (2) the matches achieved by second marriages are no better, on average, than are the matches achieved in first marriages.

Table 5: Effects of marriage, divorce and family structure on life satisfaction[1]. Ordinary least squares regression estimates. $\mathrm{N}=26,009$

\begin{tabular}{lcccc}
\hline Variable & $\mathrm{b}$ & s.e. & Standardized & $\mathrm{t}$ \\
\hline Male & -1.44 & 0.26 & -0.04 & -5.54 \\
Migrant & -0.24 & 0.51 & n.s. & -0.47 \\
Parent's education & 0.24 & 0.05 & 0.03 & 4.48 \\
Father's status & 0.88 & 0.55 & n.s. & 1.59 \\
Parent divorced & -1.97 & 0.42 & -0.03 & -4.65 \\
Number of siblings & -0.01 & 0.01 & n.s. & -0.41 \\
Marriage: & & & & \\
$\quad$ Single (reference) & -- & -- & & -- \\
First marriage & 4.42 & 0.42 & 0.11 & 10.58 \\
Second marriage & 4.01 & 0.64 & 0.05 & 6.31 \\
De facto & -0.76 & 0.62 & n.s. & -1.22 \\
Widowed & -0.49 & 0.80 & n.s. & -0.61 \\
$\quad$ Divorced & -4.50 & 0.63 & -0.06 & -7.16 \\
Family size & 0.19 & 0.10 & n.s. & 1.90 \\
Age & 0.03 & 0.01 & 0.02 & 2.99 \\
(Constant) & 66.23 & 0.69 & & \\
\hline
\end{tabular}

De facto relationships are no more satisfying than being single. This is an interesting result, because, for legal purposes, de facto couples are being treated increasingly like married couples, but the finding that these relationships are significantly less satisfying than are marriages suggests that they are quite different from marriages to the people experiencing them. 
Widows are about as satisfied with their lives as are single people. Put another way, the loss of a spouse by death drives down one's subjective well-being to the level characteristic of single people but does not, at least on average, leave the widow or widower worse off than those who have never loved and lost.

By contrast, divorce is a major blow to subjective well-being, driving life satisfaction to about 4 points below the level characteristic of single people, a substantial, statistically significant effect. Because married people are 4 points happier than are single people, and divorced people are about 4 points less happy than are the single, the transition from marriage to divorce represents a loss of about 8 points out of 100 in subjective well-being.

Thus, subjective well-being during a not uncommon marital career would begin at the single baseline, climb 4 points for marriage, drop eight points for divorce, climb up four points as a de facto relationship is formed, bringing the person back where they were when the process began, to the single baseline. For that sort of interpretation to be valid, it would have to be true that the relationship forming and breaking process depends on things other than enduring traits of the person (that it is an exogenous switching process). So far as research shows today, for the mainstream population this is largely true - trends towards later marriage (and non-marriage) and towards divorce have swept the population at all social class levels, and, moreover, at the individual level social class and other structural characteristics of individuals have little impact on divorce at the individual level. Further, we have controlled some of the potential determinants of marital careers through our family background measures in the model. The point is that a diverse spectrum of people find themselves divorced, quite possibly unhappier than they have ever been before for an extended period.

Table 5 also portrays the consequences of other features of one's family situation and life cycle stage. In particular, we find no significant effect of family size. More concretely, one’s fertility, the number of one’s children, has no systematic impact on subjective well-being there is just as much content and discontent among the prolific as among those of limited fertility and, indeed, as among the childless. We have tried a number of alternative specifications, to test the robustness of this finding and they largely turn up the same nonsignificant result, so it seem reasonable to take it as a working hypothesis that the number of one's children does not affect one's life satisfaction in Australia. This could come about either (1) because people, for the most part, achieve the family sizes they desire, and so are equally contented with them or (2) because people are sufficiently adaptable that they come to be contented with the family sizes they happen to get. This is an issue warranting future 
research, because existing research shows that the actual level of childlessness is likely substantially to exceed the desired levels of childlessness in Australia for current (and quite possibly future) cohorts of adults. If the adaptability explanation of fertility's null effect on life satisfaction is correct, then the apparent unmet demand for children will vanish as people accommodate their desires to their situation. If, on the other hand, fertility merely appears to have no impact on subjective well-being because, heretofore, people have successfully sorted themselves into the family sizes that suited them, then the unmet demand for children is likely to reduce subjective well-being in the future.

Another life course feature that is evident in Table 5 is a small, positive effect of age, such that well-being grows by about .3 points out of 100 per decade. That is very slow growth indeed, amounting to an advantage of 1.5 points for someone age 75 over someone age 25 . Nonetheless, it suggests that the aging process more than compensates for the much vaunted advantages of youth, a result that is consistent with a broad range of prior research.

Finally, note the deleterious effect of parents' divorce on offspring's later subjective wellbeing, -2 points. So even a generation later, divorce is damaging.

Another important question in issues of family effect on well-being is whether these differ by gender, for example, whether marriage is better for men than for women. To answer this question, we re-estimated the model from Table 5 separately for men and for women (Table 6). The answers are readily seen in the predicted values, setting the variables other than those representing marital status to their means, and evaluateing the regression equation for each marital status for each gender. 
Table 6: Sex differences in the effects of marriage, divorce and family structure on life satisfaction. Ordinary least squares regression estimates and predicted values.

\begin{tabular}{|c|c|c|c|c|c|c|}
\hline Variable & b & s.e. & Standardized & $\mathrm{t}$ & $\begin{array}{l}\text { Predicted } \\
\text { values[1] }\end{array}$ & $\begin{array}{c}\text { Gap: } \\
\text { Women - } \\
\text { men }\end{array}$ \\
\hline \multicolumn{7}{|c|}{ A: Women. $N=13,011$} \\
\hline Migrant & -0.63 & 0.73 & n.s. & -0.86 & & \\
\hline Parent's education & 0.19 & 0.08 & 0.03 & 2.43 & & \\
\hline Father's status & 1.69 & 0.80 & 0.02 & 2.12 & & \\
\hline Parent divorced & -1.50 & 0.59 & -0.02 & -2.52 & & \\
\hline Number of siblings & 0.02 & 0.02 & n.s. & 0.89 & & \\
\hline \multicolumn{7}{|l|}{ Marriage: } \\
\hline Single (reference) & -- & -- & & -- & 71 & 2 \\
\hline First marriage & 3.75 & 0.62 & 0.09 & 6.09 & 75 & 1 \\
\hline Second marriage & 3.47 & 0.93 & 0.04 & 3.74 & 74 & 2 \\
\hline De facto & -2.34 & 0.86 & -0.03 & -2.71 & 68 & -1 \\
\hline Widowed & -0.06 & 1.04 & n.s. & -0.06 & 71 & 5 \\
\hline Divorced & -5.99 & 0.88 & -0.08 & -6.81 & 65 & -1 \\
\hline Family size & 0.00 & 0.15 & n.s. & 0.03 & & \\
\hline Age & 0.01 & 0.01 & n.s. & 0.44 & & \\
\hline (constant) & 68.23 & 1.00 & & & & \\
\hline \multicolumn{7}{|l|}{ B: Men, $N=12,728$} \\
\hline Migrant & -0.01 & 0.72 & n.s. & -0.02 & & \\
\hline Parent's education & 0.27 & 0.07 & 0.04 & 3.70 & & \\
\hline Father's status & 0.19 & 0.77 & n.s. & 0.25 & & \\
\hline Parent divorced & -2.35 & 0.61 & -0.04 & -3.86 & & \\
\hline Number of siblings & -0.03 & 0.02 & n.s. & -1.51 & & \\
\hline \multicolumn{7}{|l|}{ Marriage: } \\
\hline Single (reference) & -- & -- & & -- & 68 & -- \\
\hline First marriage & 4.71 & 0.57 & 0.12 & 8.21 & 73 & -- \\
\hline Second marriage & 4.11 & 0.88 & 0.06 & 4.69 & 73 & -- \\
\hline De facto & 0.86 & 0.90 & n.s. & 0.95 & 69 & -- \\
\hline Widowed & -2.34 & 1.43 & n.s. & -1.63 & 66 & -- \\
\hline Divorced & -3.04 & 0.92 & -0.04 & -3.30 & 65 & -- \\
\hline Family size & 0.40 & 0.15 & 0.03 & 2.75 & & \\
\hline Age & 0.05 & 0.01 & 0.04 & 3.54 & & \\
\hline (constant) & 63.34 & 0.95 & & & & \\
\hline
\end{tabular}

[1] Predicted value for marriage groups based on the regression equation, for a person average in other respects.

We find that single women's life satisfaction averages 71 points out of 100 , all else equal (Table 6, next to last column). That is two points higher than their male peers. A first marriage elevates women's subjective well-being to 75 points, which is one point higher than their male peers. But if she enters a de facto relationship rather than a marriage, her life satisfaction is 68, actually slightly lower than had she remained single. For men, those in de facto relationships averaging 69 points in life satisfaction. Men are not significantly worse off than had they remained single, but are clearly and significantly worse off than had they 
married. Divorce drops women's life satisfaction to 65 points which is one point worse off than their male peers. A second marriage can buoy a woman's life satisfaction back up to 74, one point higher than the average for a man in the same situation. But if divorce is followed by a de facto relationship, that leaves women slightly below where they began as spinsters and brings men back to the same level of life satisfaction they experienced as bachelors. It is in widowhood that the gender differences are greatest. In general, widows are about as contented with their lives as are spinsters, ceteris paribus, but widowers average 5 points less life satisfaction than their female peers. All in all, the differences by gender are not large or systematic.

\section{Quality of marriage}

The importance of marriage to life satisfaction makes it worth inquiring into this matter more deeply. The fact that de facto relationships do not elevate well-being above the usual level for single people suggests that simply having someone else around is not enough. Accordingly, we turn to a subset of the data for which we also have available the IsssA Marital Quality Index based on people's ratings of how warm and affectionate their spouse is. The items for this index come as part of a battery asking about many different spouse characteristics, with answers on a five-point scale ranging from “definitely yes” to “definitely no”. Their exact wording:

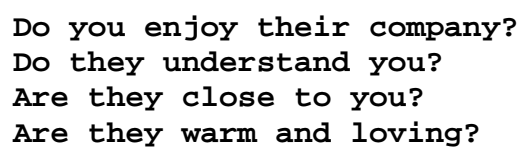

These items are very closely linked; their inter-item correlations average .75, and the reliability of the 4 item index, as measured by Cronbach’s alpha, is an excellent .92.

We re-estimate the model from Table 6 just for married people (and so omitting the indicator variables for marital status) augmenting it with the Marital Quality Index. We estimate this for the whole married population and for men and women separately (thus allowing all possible interactions with gender).

The results show that the quality of the marital relationship matters tremendously to subjective well being (Table 7). Every additional point of marital quality (one a points out of 100 basis) raises life satisfaction by about half a point for both women and men. So all marriages are not equally satisfying. 
Table 7: Quality of marriage: Effects of having a warm, affectionate marriage on life satisfaction. Ordinary least squares regression estimates. Married people only; $\mathrm{N}=2,518$ [1]

\begin{tabular}{|c|c|c|c|c|c|c|c|}
\hline \multirow[b]{2}{*}{ Variable } & \multirow[b]{2}{*}{$\mathrm{b}$} & \multirow[b]{2}{*}{ s.e. } & \multirow[b]{2}{*}{ Standardized } & \multirow[b]{2}{*}{$\mathrm{t}$} & \multicolumn{3}{|c|}{$\begin{array}{l}\text { Predicted life satisfaction } \\
\text { by quality of marriage }\end{array}$} \\
\hline & & & & & $\begin{array}{l}\text { Lowest } \\
\text { quintile }\end{array}$ & Median & $\begin{array}{l}\text { Highest } \\
\text { quintile }\end{array}$ \\
\hline A. Women, $\mathrm{N}=1,299$ & & & & & 69 & 75 & 85 \\
\hline Migrant & -1.88 & 1.97 & n.s. & -0.96 & & & \\
\hline Parent's education & -0.05 & 0.20 & n.s. & -0.24 & & & \\
\hline Father's status & 3.30 & 2.03 & n.s. & 1.63 & & & \\
\hline Parent divorced & -1.67 & 1.54 & n.s. & -1.09 & & & \\
\hline Number of siblings & 0.05 & 0.05 & n.s. & 0.88 & & & \\
\hline Family size & 1.01 & 0.36 & 0.08 & 2.80 & & & \\
\hline Q $\frac{\text { Age }}{\text { Quality }}$ of & $-\frac{0.01}{3}-\frac{0.49}{1.75}$ & $\frac{0.04}{0.02}$ & $-\frac{\text { n.s. }}{0 .} \cdot-$ & -0.25 & & & \\
\hline B. Men, $N=1,209$ & & & & & 67 & 74 & 82 \\
\hline Migrant & -0.85 & 2.02 & n.s. & -0.42 & & & \\
\hline Parent's education & 0.32 & 0.19 & n.s. & 1.65 & & & \\
\hline Father's status & -2.26 & 2.04 & n.s. & -1.11 & & & \\
\hline Parent divorced & -2.29 & 1.61 & n.s. & -1.42 & & & \\
\hline Number of siblings & -0.02 & 0.05 & n.s. & -0.41 & & & \\
\hline Family size & 0.65 & 0.36 & n.s. & 1.80 & & & \\
\hline 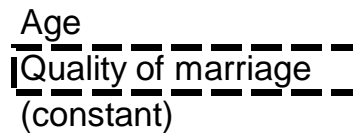 & -0.03 & $\frac{0.04}{3.0 \frac{3}{39}}$ & $-\frac{n \cdot s .}{0.43}$ & $\frac{0.74}{16.22}-1$ & & & \\
\hline
\end{tabular}

[1] The questions on quality of marriage were asked only in two recent surveys.

How does this compare to other marital statuses? To find out, we conducted a microsimulation using the regression model from Table 7, setting the values of the other variables to their means, and evaluating the equation for different levels of marital quality.

Bad marriages. Women in relationships towards the low end of marital quality - the twentieth percentile - average 69 points out of 100 in life satisfaction, all else equal. That is similar to the level of life satisfaction experienced by women in de facto relationships (68, on average). Strikingly, it is higher than the average for divorced women (65, on average) - so even a bad marriage is better than a divorce. For men, the pattern is similar: a bad marriage is fractionally worse than being in a de facto relationship but better than divorce.

Average marriages. Women in relationships of fairly typical marital quality - in the $50^{\text {th }}$ percentile - average 75 points in subjective well-being. That is substantially higher than any other marital statuses, and no less than 10 points higher than divorcees. Again, there is no substantial gender difference, with men in these typical marriages averaging 74 points. In short, a typical marriage is typically a very good thing for both parties. 
Good marriages. Women with good marriages - in the $80^{\text {th }}$ percentile of the marital quality distribution - average a striking 85 points out of 100 in life satisfaction. Men in good marriages average fully 82. Thus, a good marriage is a wonderful thing for both men and women.

\section{Discussion}

These results strongly suggest that marriage makes people happier because the security and legal recognition of a formal marriage makes for committed, loving personal relationships (H1). This commitment hypothesis yielded 100\% correct predictions. The alternatives which were all substantially less successful in their predictions (Table 1 above, last column). In particular, it suggests that unwed couples (those living together without being married) will not be as happy as married couples, because commitment is problematic; and that divorced people will be less satisfied than those in any other situation, since broken commitments are highly distressing.

Our results argue against the view that people derive subjective well-being from principally from pair bonding, which would imply that the key issue is simply the presence or absence of a partner (H2; Table 1, row 2). We find quite the contrary: when pair bonding comes without the security and legal recognition of formal marriage, it confers no benefit over being single. Moreover, when the absence of pair bonding comes because an earlier bond broke down in divorce, it is not harmless but actively detrimental to happiness. In all, the pair bonding hypothesis is correct in only $60 \%$ of its predictions.

Our results also argue against the selectivity hypothesis that people who are not very good at personal relations will predominate among the divorced, and hence among those in second marriages (H3; Table 1, row 3). This was on target for only $60 \%$ of its predictions, the key failure being its misperception of second marriages, which are in fact about as rewarding as first marriages.

Nor do the results give much support to socio-biology's reproductive-fitness hypothesis (H4: Table 1, row 4). Only 67\% of its predictions are correct. The crucial evidence against it is that having a large family has little or no beneficial effect on happiness.

The post-materialist analysis of marriage offers little insight, correct only on one prediction out of six (H5; Table 1, row 5). 
Nor does the view that people have diverse preferences but are able to sort themselves into whatever family arrangements suit them best fit the data well - just 50\% correct (H6: Table 1 , row 6). It quite misses the central fact that marriage is better than any other arrangement and that not everyone who wants to marry is able to do so.

Finally the conflictual views that men and women have sharply different preferences and that men are dominant, getting what they want (H7), or alternatively that women are dominant and get what they want (H8), both fail to gain support (Table 1, rows 7 and 8). Overall, both are correct in just $50 \%$ of their predictions.

In short, commitment is the key: the security and legal recognition of a formal marriage makes for committed, loving personal relationships, which makes people happier. Hence anything that facilitates marriage is a gain and anything that hinders it is a loss.

The importance of commitment has important practical implications. To elucidate the implications, let us follow a typical person through the family life-cycle. Starting off unmarried, our baseline, a typical Australian woman with an average family background has a life satisfaction score of about 71 points out of 100, a few points higher than a comparable man. (1) In the most traditional pattern, she will then marry. Her life satisfaction then rises about 4 points, and stays at that higher level for many years, regardless of how many children she has. If she eventually becomes a widow, her life satisfaction will then drop back to what it was early in life when she was single. Averaging over the course of a lifetime, this traditional pattern results in a mean level of satisfaction of 73.9 points (Table 8, row 1). For men, the pattern is similar, with the average 72.2 points. We next compare this traditional pattern with some more modern alternatives. 
Table 8. Implications for different family life-cycle patterns. Micro-simulation based on Table 6 .

\begin{tabular}{lccccc}
\hline & \multicolumn{2}{c}{ Women } & & \multicolumn{2}{c}{ Men } \\
\cline { 2 - 3 } \cline { 5 - 6 } Family life-cycle pattern & $\begin{array}{c}\text { Change in } \\
\text { Mean life }\end{array}$ & $\begin{array}{c}\text { Chatisfaction } \\
\text { satisfaction } \\
\text { (\% of row 1) }\end{array}$ & & $\begin{array}{c}\text { Mean life } \\
\text { satisfaction }\end{array}$ & $\begin{array}{c}\text { Change in } \\
\text { satisfaction } \\
\text { (\% of row 1) }\end{array}$ \\
\hline 1. Traditional: Marriage, no divorce[a] & 73.9 & -- & & 72.2 & -- \\
2. Marriage, early divorce, remarriage[b] & 73.0 & $-1.3 \%$ & & 71.1 & $-1.5 \%$ \\
3. Marriage, early divorce, no remarriage[c] & 66.4 & $-10.2 \%$ & & 66.0 & $-8.6 \%$ \\
4. Marriage, mid-life divorce, no remarriage[d] & 68.6 & $-7.2 \%$ & & 67.9 & $-5.9 \%$ \\
5. No marriage, live as unmarried couple[e] & 69.2 & $-6.5 \%$ & & 68.8 & $-4.7 \%$ \\
6. Marriage, early divorce, then live as unmarried & & & & & $-4.7 \%$ \\
\hline
\end{tabular}

[a] Begin age 18; women marry at 25 and men at 27; never divorce. Women widowed at 76 , men never. Men live to 77 and women to 82. Life expectancy data from the Australian Bureau of Statistics at www.abs.gov.au/ausstats/abs@.nsf/lookup/nt0001dcd6, cat. no. 3302.0.

[b] As pattern 1 but divorce after 5 years marriage; remarry 5 years later. Both first and second marriages of average quality.

[c] As pattern 2 but never remarry.

[d] As pattern 1 but divorce at 45 and never remarry.

[e] As pattern 1 but begin co-habiting at 25 .

[f] As pattern 2 but co-habit rather than remarry.

In recent decades, marriage might well end in divorce rather than widowhood. The divorce would be a disaster in the short run, loosing all the gains of marriage and more besides, leaving a woman fully 6 points worse off than when she was single. Strikingly, even staying in a bad marriage - one in the lowest quintile of marital quality - is better than divorce. However if she eventually remarries, all is well again: second marriages are just as rewarding as first marriages. ${ }^{3}$ Over the full life-cycle, her life satisfaction would average 73.0 points, about $1 \%$ lower than had she followed the traditional path (Table 8, row 2). ${ }^{4}$ The pattern for men is essentially the same. So an early divorce followed by remarriage - a common modern pattern - seems to make for only a slightly worse life than a traditional stable marriage, with the loss attributable mainly to the unhappy gap between first and second marriages. Perversely, if one spouse falls in love with someone else, breaks up the marriage, and

\footnotetext{
3 Thus the benefits of leaving a bad marriage depend crucially on the probability that the bad marriage would stay bad over the years (about which the evidence is equivocal); on the length of time one is likely to stay divorced before remarrying (longer for older women than for younger); and on the quality of the new marriage.

${ }^{4} \mathrm{Viz}(73.0-73.9) / 73.9=-.01=1 \%$. The simulation assumes that both first and second marriages are average in marital quality - longitudinal data suggest that is not an entirely unreasonable assumption - and that the divorce is equally harmful to both spouses. A more realistic assumption would be that the first marriage was below average quality, at least for one spouse, and that the spouse mainly responsible for breaking up the marriage looses less by divorce while the other spouse looses more.
} 
promptly marries their lover, they loose little while the innocent spouse, taking longer to remarry, looses much more.

But if divorce does not quickly lead to remarriage, the result is an unmitigated disaster (Table 8 , row 3). For women, lifetime satisfaction is then fully $10 \%$ lower than in a traditional marriage; for men it is $8 \%$ or $9 \%$ lower. So a divorce - particularly when there are children to inhibit remarriage - can be disastrous.

A mid-life divorce that does not (as is often the case) lead to a prompt remarriage is also very bad, although not quite as disastrous: a drop of $7 \%$ in lifetime satisfaction for women and $6 \%$ for men. It is not quite as bad as an early divorce simply because there are more good years of marriage before the divorce.

Living together as an unmarried couple, a pattern increasingly common in recent decades in most Western nations, reduces life satisfaction substantially: the lack of commitment is costly. In the extreme where co-habitation never leads to marriage, lifetime satisfaction is $6 \%$ or $7 \%$ lower for women and $5 \%$ lower for men (Table 8 , row 5). Nor is the mixed pattern of marriage, early divorce, followed by long-term unmarried co-habitation any better (Table 8, row 6).

The public policy implications of these findings for tax and welfare policies are several. First, anything that encourages marriage is good and anything that encourages divorce is bad. Even a poor marriage - one in the lowest quintile of marital quality - is better than divorce while a good marriage is an unsurpassed passport to happiness. Thus it may well be that liberalizing divorce laws, as has happened in many Western nations in recent decades, is not a good idea. Divorce followed by prompt re-marriage of both partners is probably harmless, even if not obviously beneficial. But a divorce that leaves one or both parties unmarried for any lengthy period does substantial harm. At a minimum, our findings suggest a very cautious approach toward liberalization of divorce laws.

Our findings also suggest that encouraging unmarried co-habitation is harmful if the alternative is formal marriage, harmless if the alternative is remaining single, and beneficial only if the alternative is remaining divorced. Given this mixed picture, broad based policies encouraging co-habitation (such as tax concessions or legal rights similar to those for married couples) would seem unwise.

In short, traditional marriage patterns increase the sum of human happiness. A less traditional pattern of early divorce followed by an enduring second marriage is little worse. But the 
increasingly common modern patterns of divorce without remarriage, or long lasting cohabitation without formal marriage, reduce the sum of human happiness by $5 \%$ to $10 \%$.

\section{References}

Andrews, F.M. and S. B. Withey. 1976. Social Indicators of Well-being. New York: Plenum.

Australian Bureau of Statistics. 2000. Australian Social Trends 2000. Canberra: Australian Bureau of Statistics, Cat. no. 4102.0.

Bean, Clive S. 1991. “Comparison of National Social Science Survey with the 1986 Census”. NSSS Report, Suppl.(2)6: 12-19. Available at www.international-survey.org

Becker, Gary S. 1991. A Treatise on the Family. Enlarged Edition. Cambridge, MA: Harvard University Press.

Bennett, Neil G. , Ann K. Blanc, and David E. Bloom. 1988. "Commitment and the Modern Union.” American Sociological Review 53 (Feb): 127-138.

Bernard, Jesse. 1982. The Future of Marriage. New Haven: Yale University Press.

Cantril, H. 1965. The Pattern of Human Concerns. New Brunswick: Rutgers University Press.

Castles, Francis G. 1999. Comparative Public Policy. Edward Elgar.

Cherlin, Andrew. 1992. Marriage, Divorce, Remarriage. Cambridge, MA: Harvard University Press.

Cummins, Robert A. 1998. "The second approximation to an international standard for life satisfaction.” Social Indicators Research 43 (3): 307-334.

Davis, James. 1984. “New money, an old man/lady, and 'Two’s Company’: Subjective Wellbeing in the NORC General Social Surveys, 1972-1982.” Social Indicators Research 15: 319-350.

Diener, Ed, Carol L. Gohm, Eunkook Suh, and Shigehiro Oishi. 2000. "Similarity of the Relations between Marital Status and Subjective Well-Being across Cultures.” Journal of Cross Cultural Psychology 31(4): 419-436 
Dillman, Don A. 1993. "The Design and Administration of Mail Surveys" Annual Review of Sociology 17: 225-49.

Eaves, L.J., N.G. Martin, A.C. Heath , J.K. Hewitt, and M.C. Neale. 1990. "Personality And Reproductive Fitness.” Behavior Genetics 20 (5): 563-568.

Evans, M.D.R. and Jonathan Kelley. 2002, in press. Australian Economy and Society: Volume 1- Education, Work and Welfare 2001. Sydney: Federation Press.

Forest, Kay B. 1996. “Gender and the Pathways to Subjective Well-Being.” Social Behavior and Personality 24(1): 19-34.

Frijters, Paul. 1999. Explorations of Welfare and Well-being. Tinbergen Institute Research Series \#196. Amsterdam: Thela Thesis.

Haring-Hidore, Marilyn, William A. Stock, Morris A. Okun, and Robert A. Witter. 1985. "Marital Status and Subjective Well-Being: A Research Synthesis.” Journal of Marriage and the Family 47(4): 947-953

Headey, Bruce and Alexander Wearing. 1990. “Subjective Well-Being and Coping with Adversity.” Social Indicators Research 22(4): 327-349.

Headey, Bruce and Alexander Wearing. 1992. Understanding Happiness: A Theory of Subjective Well-being. Melbourne: Longman Cheshire.

Headey, Bruce. 1988. “The life satisfactions and priorities of Australians”. Pps 163-175 in Jonathan Kelley and Clive Bean (Editors). Australian Attitudes: Social and Political Analyses from the National Social Science Survey. Sydney: Allen and Unwin.

Headey, Bruce. 1993. “An Economic Model Of Subjective Well-Being: Integrating Economic And Psychological Theories.” Social Indicators Research 28(2): 97-116

Inglehart, Ronald (1997): Modernization and Postmodernization, Princeton, Princeton University Press.

Johnson, David R. and Alan Booth. 1998. "Marital Quality: A Product of the Dyadic Environment or Individual Factors?” Social Forces 76 (March): 883-904 
Kahneman, D., E. Diener, and N. Schwarz (editors). 1998. Foundations of Hendonic Psychology: Scientific Perspectives on Enjoyment and Suffering. New York: Russel Sage Foundation.

Kelley, Jonathan, and M.D.R. Evans. 1999 "Australian and International Survey Data for Multivariate Analysis: The IsssA." Australian Economic Review 32(3):298-302.

Kelley, Jonathan, M.D.R. Evans and Peter Dawkins. 1998. "Job Security in the 1990s: How much is Job Security Worth to Employees?” Australian Social Monitor 1(1):1-7.

Kirk K.M., S.P. Blomberg, D.L. Duffy, A.C. Heath, I.P.F. Owens, and N.G. Martin 2001. "Natural Selection and Quantitative Genetics of Life-History Traits in Western Women.” Evolution 55 (2): 423-435.

Kurdek, Lawrence A. 1990. "Divorce History and Self-Reported Psychological Distress in Husbands and Wives.” Journal of Marriage and the Family 52(Aug): 701-708

Leiblum, Sandra R. 1993. "The Impact of Infertility on Sexual and Marital Satisfaction.” Annual Review of Sex Research 4: 99-120

Macklin, Eleanor D. 1978. “Nonmarital Heterosexual Cohabitation.” Marriage and Family Review 1(March-April): 1-12.

Marks, Gary N. and N. Fleming. 1999. "Influences And Consequences Of Well-Being Among Australian Young People: 1980-1995.” Social Indicators Research 46 (3): 301323.

Mastekaasa, Arne. 1993. "Marital Status and Subjective Well-Being.” Social Indicators Research 29(3): 249-276.

Mastekaasa, Arne. 1994. "The subjective well-being of the previously married.” Social Forces 73: 665-82.

Mastekaasa, Arne. 1995. "Marital Dissolution and Subjective Distress: Panel Evidence.” European Sociological Review 11(2): 173-185.

Oropesa, R. S. 1995. “Consumer Possessions, Consumer Passions, and Subjective WellBeing.” Sociological Forum 10(2): 215-244. 
Rindfuss, Ronald R. and Audrey VandenHeuvel. 1990. “Cohabitation: An alernative to Marriage or a Precursor to Being Single?” Population and Development Review 16 (December): 703-726.

Rogers, Stacy J. 1999. “The Nexus of Job Satisfaction, Marital Satisfaction and Individual Well-Being: Does Marriage Order Matter? Research in the Sociology of Work 7: 141-167.

Sikora, Joanna. 1997. "International Survey of Economic Attitudes in Australia, Finland and Poland: Comparison with the Census”. WwA: Worldwide Attitudes 1997.12.31:1-8. Available at www.international-survey.org.

van Dijk, J.J.M., Pat Mayhew, and M. Killias. 1990. Experiences of Crime Across the World: Key Findings from the 1989 International Crime Survey. Boston: Kluwer Law \& Taxation.

Van Praag, B.M.S. 1971. "The welfare function of income in Belgium: An empirical investigation” European Economic Review (2):337-369.

Veenhoven. R. 1984. Conditions of Happiness. Dordrecht: Reidel.

Vining, Daniel R. 1986. “Social versus Reproductive Success: The Central Theoretical Problem of Human Sociobiology.” Behavioral and Brain Sciences 9(1): 167-187.

Waite, Linda J. and Maggie Gallagher. 2000. The Case for Marriage. New York: Doubleday.

Wearing, Alex J. and Bruce Headey. 1998. "Who enjoys life and why: measuring subjective well-being.” Pp 169-182 in R. Eckersley ( ed.) Measuring Progress: Is Life Getting Better? Collingwood, Vic: CSIRO Publishing.

Wilkinson, Ross B.1995. “Changes in Psychological Health and the Marital Relationship through Childbearing: Transition or Process as Stressor?” Australian Journal of Psychology 47 (2): 86-92.

Williams, Kristi L. 2001. “The Effects of Marital Status and Marital Quality on Mental and Physical Health: A Re-Evaluation and Clarification of Gender Differences.” Unpublished Doctoral Dissertation, University of Texas at Austin. 